\title{
Anti-Mycobacterium tuberculosis activity and cytotoxicity of Calophyllum brasiliense Cambess (Clusiaceae)
}

\author{
Claudia Terencio Agostinho Pires ${ }^{1}$, Mislaine Adriana Brenzan², \\ Regiane Bertin de Lima Scodro ${ }^{2,3}$, Diógenes Aparício Garcia Cortez ${ }^{2,4}$, \\ Luciana Dias Ghiraldi Lopes ${ }^{3}$, Vera Lucia Dias Siqueira ${ }^{2,3}$, Rosilene Fressatti Cardoso ${ }^{1,3} /+$
}

\footnotetext{
${ }^{1}$ Programa de Pós-Graduação em Biociências Aplicadas à Farmácia ²Programa de Pós-Graduação em Ciências Farmacêuticas ${ }^{3}$ Departamento de Análises Clínicas e Biomedicina ${ }^{4}$ Depatamento de Farmácia, Universidade Estadual de Maringá, Maringá, PR, Brasil
}

We evaluated the in vitro anti-Mycobacterium tuberculosis activity and the cytotoxicity of dichloromethane extract and pure compounds from the leaves of Calophyllum brasiliense. Purification of the dichloromethane extract yielded the pure compounds (-) mammea A/BB (1), (-) mammea B/BB (2) and amentoflavone (3). The compound structures were elucidated on the basis of spectroscopic and spectrometric data. The contents of bioactive compounds in the extracts were quantified using high performance liquid chromatography coupled to an ultraviolet detector. The anti-M. tuberculosis activity of the extracts and the pure compounds was evaluated using a resazurin microtitre assay plate. The cytotoxicity assay was performed in J774G.8 macrophages using the 3-(4,5-dimethyl thiazol-2-yl)2,5-diphenyl tetrazolium bromide colourimetric method. The quantification of the dichloromethane extract showed (1) and (2) at concentrations of $31.86 \pm 2.6$ and $8.24 \pm 1.1 \mu \mathrm{g} / \mathrm{mg}$ of extract, respectively. The dichloromethane and aqueous extracts showed anti-M. tuberculosis $H_{37} R v$ activity of 62.5 and $125 \mu \mathrm{g} / \mathrm{mL}$, respectively. Coumarins (1) and (2) showed minimal inhibitory concentration ranges of 31.2 and $62.5 \mu \mathrm{g} / \mathrm{mL}$ against $\mathrm{M}$. tuberculosis $H_{37} R v$ and clinical isolates. Compound (3) showed no activity against $\mathrm{M}$. tuberculosis $\mathrm{H}_{3} \mathrm{Rv}$. The selectivity index ranged from 0.591.06. We report the activity of the extracts and coumarins from the leaves of $\mathrm{C}$. brasiliense against $\mathrm{M}$. tuberculosis.

Key words: Mycobacterium tuberculosis - Calophyllum brasiliense - coumarin -

cytotoxicity - 3-(4,5-dimethyl thiazol-2-yl)-2,5-diphenyl tetrazolium bromide

Tuberculosis (TB) is a serious public-health problem, with increasing mortality rates worldwide (WHO 2012). The search for new drugs to treat TB is of paramount importance in view of the present long-term combination therapy, the large number of side effects associated with most drugs and the continuous selection of resistant strains (Boogaard et al. 2009, León-Díaz et al. 2010).

Species from the genus Calophyllum sp. (Clusiaceae) have aroused interest from the scientific community because of promising results from chemical and biological aspects. This genus is rich in secondary metabolites such as steroids, triterpenes, coumarins, benzopyrans and several types of xanthones and proanthocyanins, some of which possess antibacterial potential (Cronquist 1981). The pyranocoumarin (+)-calanolide A from Calophyllum lanigerum showed significant activity against Mycobacterium tuberculosis, including multidrug-resistant (MDR) strains, with a minimal inhibitory concentration (MIC) of $3.13 \mu \mathrm{g} / \mathrm{mL}$ and anti-human immunodeficiency virus (HIV)-1 activity, indicating a new class of

doi: $10.1590 / 0074-0276130323$

Financial support: CNPq, CAPES

+ Corresponding author: rfcardoso@uem.br

Received 18 June 2013

Accepted 19 December 2013 compounds that can be used to treat patients co-infected with HIV/TB (Xu et al. 2004).

Calophyllum brasiliense Cambess (Clusiaceae) is a large tree that is widely distributed in the Americas. It grows in tropical forests from Mexico to Brazil, where it is known as "Guanandi" (Corrêa 1978). In Brazil folk medicine, infusions prepared from the stem bark are used in the treatment of rheumatism, varicosis, haemorrhoids, chronic ulcers (Corrêa 1978), bronchitis, gastric and hepatic disturbances (Noldin et al. 2006) and pain (Lewis 1977).

C. brasiliense has proven to be a rich source of bioactive compounds, including the coumarins mammea A/ $\mathrm{BA}$, mammea A/BB (1), mammea A/AA, mammea C/ $\mathrm{OA}$ and mammea C/OB, which act against Staphylococcus aureus (Reyes-Chilpa et al. 2004, Yasunaka et al. 2005). Some chromanone acids isolated from C. brasiliense bark showed moderate to strong activity against Bacillus cereus and Staphylococcus epidermidis (Cottiglia et al. 2004). Assays using methanolic extracts of the roots, stems, leaves, flowers and fruits from $C$. brasiliense indicated that all parts of the plant exhibited activity against Gram-positive bacteria (B. cereus, $S$. aureus, Staphylococcus saprophyticus and Streptococcus agalactiae). No activity was observed against Gramnegative bacteria (Enterobacter cloacae, Escherichia coli, Proteus mirabilis, Pseudomonas aeruginosa and Salmonella typhimurium) and yeasts (Candida albicans and Candida tropicalis) (Pretto et al. 2004). Other studies have shown that the extracts, especially the coumarin 
(-) (1) isolated from C. brasiliense leaves, possess potent antileishmanial activity (Brenzan et al. 2007, 2008a, b, 2012, Honda et al. 2010, Tiuman et al. 2012).

The aim of the present study was to assess the in vitro antimycobacterial activity and cytotoxicity of the dichloromethane extract and the compounds (1), (-) mammea B/BB (2) and amentoflavone (3) obtained from the leaves of $C$. brasiliense.

\section{MATERIALS AND METHODS}

Plant material - C. brasiliense leaves were collected in Cardoso Island, December 2010, in the state of São Paulo (SP), Brazil. The voucher specimen (SP 363818) was identified by Prof Dr Maria Claudia M Young and was deposited and authenticated at the Herbarium of the Botany Institute of São Paulo, SP. The leaves were dried at $35^{\circ} \mathrm{C}$ in a circulating air oven and triturated in a knife mill (Usiram, São Bernardo do Campo, SP).

Plant extraction and purification of compounds - The powdered leaves $(800 \mathrm{~g})$ were extracted by exhaustive maceration in ethanol/water (9:1) at room temperature (RT), filtered and concentrated under vacuum at $40^{\circ} \mathrm{C}$ to obtain an aqueous extract and a dark-green residue. The aqueous extract was lyophilised (121.3 g). The dark-green residue from the extract, which had adhered to the glass bottles, was dissolved with dichloromethane and the solvent was completely evaporated at RT to yield a dichloromethane extract (25.0 g) (Brenzan et al. 2007, 2008a, b).

The dichloromethane extract $(25.0 \mathrm{~g})$ was initially fractionated using chromatography in a vacuum silicagel column $(8.0 \times 40 \mathrm{~cm})$ with hexane, hexane/dichloromethane (1:1), dichloromethane, dichloromethane/ ethyl acetate (9:1), ethyl acetate, methanol and methanol/ water (9:1). Next, the hexane fraction $(4.0 \mathrm{~g})$ was further chromatographed on a vacuum silica-gel column and eluted with hexane, hexane/dichloromethane (98:2, 95:5, 90:10, 80:20 and 50:50), dichloromethane, dichloromethane/ethyl acetate (98:2, 95:5, 90:10, 80:20 and 50:50), ethyl acetate and methanol. The hexane fraction was evaporated to a residue, which was crystallised using dichloromethane (9:1), yielding compound (1) (52.0 $\mathrm{mg}$ ), as described in previous studies (Gasparotto-Júnior et al. 2005, Brenzan et al. 2007, 2008a, b). Fractions 6-8 $(667.0 \mathrm{mg})$, which were eluted in hexane, were chromatographed using thin layer chromatography and combined and then rechromatographed on a silica-gel column chromatograph $(40 \times 2.0 \mathrm{~cm})$ eluted with hexane, hexane/dichloromethane (98:2-50:50), dichloromethane, dichloromethane/ ethyl acetate (95:5-50:50), ethyl acetate and finally methanol. Next, fractions $1-12$, which were eluted in hexane, were combined and evaporated to dryness, obtaining (2) (10.5 mg), as described in a previous study (Brenzan et al. 2008b). The ethyl acetate fraction $(1.83 \mathrm{~g})$ of the dichloromethane extract was rechromatographed through a Sephadex LH-20 column and eluted with chloroform/methanol (1:1). Fractions 48-53 (223.8 $\mathrm{mg}$ ) were identified as (3), as described in a previous study (Brenzan et al. 2008a).

Structure elucidation - The compounds were identified by chromatography-mass spectrometry in a Shi- madzu GC/MS 17 A QP 5000 mass spectrometer, DB5 column $(30 \mathrm{~m} ; 0.32 \mu \mathrm{m})$ and a Micromass Quattro-LC instrument equipped with an ESI/APCI Z-spray ion source and by nuclear magnetic resonance (NMR) obtained in a Bruker DRX-400 (8.4 T) and Gemini 300 (7.05T), with TMS as the internal standard and a constant temperature of $298 \mathrm{~K} .{ }^{1} \mathrm{H}$ NMR $(300 \mathrm{MHz}),{ }^{13} \mathrm{C}$ NMR $(75.5 \mathrm{MHz})$, DEPT, COSY (300 MHz), HMBC and HSQC analysis was conducted using deuterated solvent $\left(\mathrm{CDCl}_{3}\right)$. The $\alpha_{\mathrm{D}}$ was obtained using a Perkin-Elmer Model 241 polarimeter $\left(20^{\circ} \mathrm{C} ; 589 \mathrm{~nm}\right)$ with dichloromethane and was compared with data from the literature (Gasparotto-Júnior et al. 2005, Brenzan et al. 2008a, b, 2010).

Spectroscopic and spectrometry data - The spectroscopic and spectrometry data of compounds (1), (2) and (3) (Fig. 1) were obtained from previous studies (Gasparotto-Júnior et al. 2005, Brenzan et al. 2008a, b, 2010, respectively).

High performance liquid chromatography coupled to a ultraviolet detector (HPLC-UV) analysis - The dichloromethane extract and purified compounds were analysed by HPLC-UV using HPLC-UV grade solvents and ultrapure water (Milli-Q system, Millipore, Bedford, MA, USA) and a Waters 1525 liquid chromatograph equipped with a binary pump (LC-10 AD), automatic injection valve 135 (Rheodyne) with a $20 \mu \mathrm{L}$ loop, CTO-10AVP thermostat-controlled oven compartment (Shimadzu) and a $2489 \mathrm{UV} /$ visible detector (Waters) controlled by Breeze 2 software (OmniSolv EM Science, Gibbstown, NJ, USA). A MetaSil ODS column $(5 \mu \mathrm{m} ; 150 \times 4.6 \mathrm{~mm})$ maintained at $25^{\circ} \mathrm{C}$ was used in the chromatographic analysis. The separation was conducted in a gradient system, using a mixture of acetonitrile and ultrapure water $55: 45 \mathrm{v} / \mathrm{v}$ to $80: 20(0-10 \mathrm{~min}), 80: 20 \mathrm{v} / \mathrm{v}$ to $100 \%(10-20 \mathrm{~min}), 100 \%$ acetonitrile $(20-25 \mathrm{~min})$ and $55: 45 \mathrm{v} / \mathrm{v}(26-30 \mathrm{~min})$ as the mobile phase, at a flow rate of $0.6 \mathrm{~mL} / \mathrm{min}$. Detection was performed at $336 \mathrm{~nm}$ and the running time was 30 min. The sample injection volume was $20 \mu \mathrm{L}$. The dichlo-
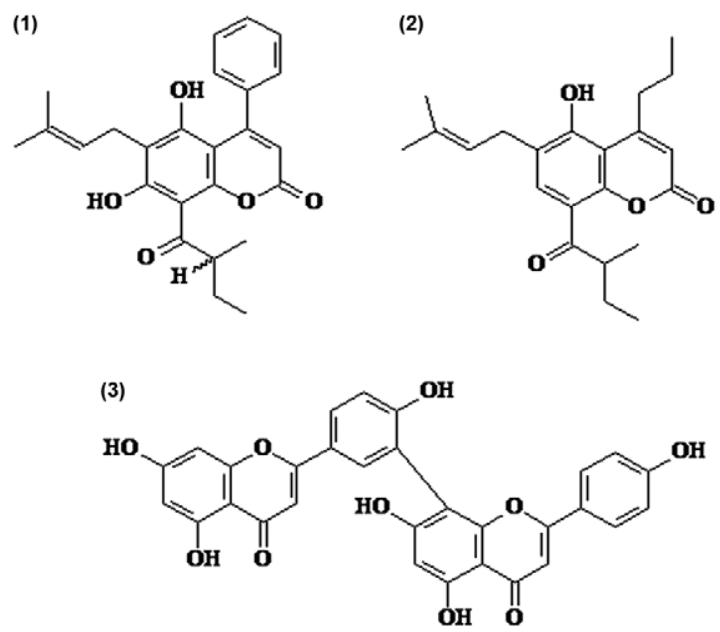

Fig. 1: pure compounds isolated from leaves of Calophyllum brasiliense: (-) mammea A/BB (1), (-) mammea B/BB (2) and amentoflavone (3). 
romethane extract $(3 \mathrm{mg} / \mathrm{mL})$ and purified compounds (1), (2) and (3) $(1 \mathrm{mg} / \mathrm{mL})$ were dissolved in methanol, filtered through a membrane filter (Millipore, Brazil) and injected $(20 \mu \mathrm{L})$ into the HPLC-UV system. Compounds (1) and (2) were quantified in the dichloromethane and aqueous extracts by HPLC-UV using compound (1) isolated from the $C$. brasiliense leaves as the standard. The content of (2) was calculated using the calibration curves of compound (1); these compounds belong to the same coumarin class and produced UV-spectra with almost the same molar absorptivity at 254 and $366 \mathrm{~nm}$ (Crombie et al. 1987, Gasparotto-Júnior et al. 2005). For the calibration curves of compound (1), solutions in methanol were used at concentrations ranging from $15.63-250 \mu \mathrm{g} / \mathrm{mL}$. The extracts were prepared in methanol at $3 \mathrm{mg} / \mathrm{mL}$ and filtered through a $0.45-\mu \mathrm{m}$ membrane filter (Millipore, Brazil). Three determinations were carried out for each sample. The statistical analyses of the data were performed using Statistica 8.0 software (Statsoft Inc, Tulsa, OK, USA).

Determination of antimycobacterial activity - To determine the MIC against M. tuberculosis $\mathrm{H}_{37} \mathrm{Rv}$ (ATCC 27294), the dichloromethane and aqueous extracts from C. brasiliense leaves and purified compounds (1), (2) and (3) were subjected to in vitro assays in triplicate. Additionally, the pure compounds were tested against 13 clinical isolates (6 susceptible and 7 resistant). The clinical isolates were obtained from the mycobacteria collection of the Laboratory of Medical Bacteriology of the State University of Maringá, state of Paraná, Brazil. The antimycobacterial activity was evaluated using REMA, according to the procedure by Palomino et al. (2002) and Scodro et al. (2013). Briefly, $200 \mu \mathrm{L}$ of sterile distilled water was distributed into the outer wells of a microplate (Falcon 3072, Becton-Dickinson, Lincoln Park, NJ, USA). The extracts and pure compounds were diluted in dimethyl sulphoxide (DMSO) (Amresco) and serial two-fold dilutions from 1,000-7.8 $\mu \mathrm{g} / \mathrm{mL}$ and 250 $1.9 \mu \mathrm{g} / \mathrm{mL}$, respectively, were made in Middlebrook 7H9 (Difco Laboratories, Detroit, MI, USA) supplemented with oleic acid, bovine albumin, dextrose and catalase (OADC) enrichment (BBL/Becton-Dickinson, Sparks, MD, USA). Isoniazid (Difco) was used as the reference drug at concentrations from 1.0-0.007 $\mu \mathrm{g} / \mathrm{mL}$. One hundred microlitres of each bacterial inoculum, standardised according to 1 McFarland turbidity and diluted 1:20 in Middlebrook 7H9 medium supplemented with OADC, was inoculated into the wells. A growth control containing no drug and a sterile control without bacteria were prepared for each assay. A control containing $2.5 \%(\mathrm{v} / \mathrm{v})$ DMSO was included to detect inhibitory effects on $M$. tuberculosis growth. The plates were covered with lids and the edges were sealed with polyethylene tape. The plates were placed in a plastic box and incubated at $35^{\circ} \mathrm{C}$ at normal atmosphere for seven days. Next, $30 \mu \mathrm{L}$ of freshly prepared $0.01 \%$ resazurin solution (Acros, Morris Plains, NJ, USA) was added to each well and the plates were reincubated for $24-48 \mathrm{~h}$ at $35^{\circ} \mathrm{C}$ for visual readings. A colour change from blue to pink indicated mycobacterial growth and the MIC was interpreted as the lowest concentration that prevented the colour change.
Cytotoxicity assay - In vitro cytotoxicity assays were performed on J774G.8 macrophages (Papazisis et al. 1997). The macrophages were maintained in tissue flasks containing RPMI-1640 medium (Gibco, Invitrogen Co, Grand Island, NY, USA) with L-glutamine and supplemented with $10 \%$ inactivated foetal bovine serum (FBS) (Gibco BRL, Life Technologies) at $37^{\circ} \mathrm{C}$ in a $5 \% \mathrm{CO}_{2}$ atmosphere. The macrophages were plated at $5.0 \times 10^{\frac{2}{4}}$ cells per well in a 96-well microplate with RPMI-1640 medium supplemented with $10 \%$ inactivated FBS and incubated for $24 \mathrm{~h}$ at $37^{\circ} \mathrm{C}$ in $5 \% \mathrm{CO}_{2}$. Next, the medium was removed and the cell monolayers were treated with different concentrations of the extracts and pure compounds (500-3.12 $\mu \mathrm{g} / \mathrm{mL})$. Positive and negative controls (without drugs) were included. The microplate was incubated under the same conditions for $48 \mathrm{~h}$. Subsequently, 3-(4,5-dimethyl thiazol-2-yl)-2,5-diphenyl tetrazolium bromide dissolved in phosphate buffered saline at a concentration of $2 \mu \mathrm{g} / \mathrm{mL}$ was added to all of the wells except the reaction blank (Mosmann 1983). The microplate was incubated in the absence of light under $5 \% \mathrm{CO}_{2}$ at $37^{\circ} \mathrm{C}$ for $4 \mathrm{~h}$. Next, $150 \mu \mathrm{L}$ of DMSO was added and stirred and the optical density was determined using an automated spectrophotometer (Asys Expert Plus) at 492 $\mathrm{nm}$. The $50 \%$ cytotoxicity concentration $\left(\mathrm{IC}_{50}\right)$ was determined by logarithm regression analysis. The selectivity index (SI) was determined using the $\mathrm{IC}_{50} / \mathrm{MIC}$ ratio for each compound tested.

\section{RESULTS}

The dichloromethane extract showed activity against M. tuberculosis $\mathrm{H}_{37} \mathrm{Rv}$ with a MIC of $62.5 \mu \mathrm{g} / \mathrm{mL}$. The aqueous extract showed lower activity (MIC $125 \mu \mathrm{g}$ / $\mathrm{mL}$ ) (Table I).

The fractionation of the dichloromethane extract led to the isolation of the coumarins (1) and (2) and the biflavonoid (3), with the last one as the major constituent of the extract (Fig. 1). The spectral data of the compounds were in agreement with the literature (Gasparotto-Júnior et al. 2005, Brenzan et al. 2007, 2008a, b, 2010).

The dichloromethane and aqueous extracts were analysed using HPLC-UV. These extracts displayed similar chromatographic profiles at $336 \mathrm{~nm}$. In both extracts, we identified compounds (1) (peak 1), (2) (peak 2) and (3) (peak 3) with retention times of 21.0, 15.5 and 5.5 min, respectively (Fig. 2). For the determination of the contents of compounds (1) and (2) in the extracts from $C$. brasiliense, the regression equation $y=61589 x+52298$ was used, which showed different concentrations of the compounds. The dichloromethane extract showed a significantly higher concentration of compound (1) (31.86 \pm $2.6 \mu \mathrm{g} / \mathrm{mg})$ than the aqueous extract $(16.67 \pm 1.4 \mu \mathrm{g} / \mathrm{mg})$ $(\mathrm{p}<0.001)$. Compound (2) was detected at a concentration of $8.24 \pm 1.1 \mu \mathrm{g} / \mathrm{mg}$ in the dichloromethane extract, but it was not possible to quantify (2) in the aqueous extract. Compound (3) was not quantified because it did not demonstrate activity.

Both coumarins (1) and (2) isolated from the dichloromethane extract showed anti-M. tuberculosis $\mathrm{H}_{37} \mathrm{Rv}$ activity, with a MIC of $31.2 \mu \mathrm{g} / \mathrm{mL}(76.85 \mu \mathrm{M})$ and 31.2 $\mu \mathrm{g} / \mathrm{mL}(83.87 \mu \mathrm{M})$, respectively (Table I). Compound (3) 
showed low activity against $M$. tuberculosis $\mathrm{H}_{37} \mathrm{Rv}$ (MIC $>500 \mu \mathrm{g} / \mathrm{mL}$ ) (Table I).

We also evaluated the antimycobacterial activity of compounds (1) and (2) against six susceptible and seven resistant clinical M. tuberculosis isolates. The MIC values ranged between (1) $31.2 \mu \mathrm{g} / \mathrm{mL}(76.85 \mu \mathrm{M})$ and 62.5 $\mu \mathrm{g} / \mathrm{mL}(153.94 \mu \mathrm{M})$ and $(2) 31.2 \mu \mathrm{g} / \mathrm{mL}(83.87 \mu \mathrm{M})$ and $62.5 \mu \mathrm{g} / \mathrm{mL}(168.01 \mu \mathrm{M})$ (Table II).

The cytotoxicity assays, which were used to evaluate the safety of these compounds for mammalian cells, were performed only with the dichloromethane extract and pure compounds (1) and (2), which showed antimycobacterial activity. The dichloromethane extract and the pure compounds showed SI ranges from 0.59-1.06 (Table I).

\section{DISCUSSION}

In the present study, we evaluated the antimycobacterial activity of dichloromethane and aqueous extracts from the leaves of C. brasiliense and pure compounds (1), (2) and (3) isolated from the dichloromethane extract.

No relevant difference in MIC values between the dichloromethane and aqueous extracts were detected against M. tuberculosis $\mathrm{H}_{37} \mathrm{Rv}$ in this study. The similarity in the MIC values for the nonpolar and polar extracts may be attributed to the coumarin contents in the aqueous extract, which was demonstrated by HPLC-UV, albeit at lower concentrations than that in dichloromethane extracts.

The MIC values of coumarins (1) and (2) isolated from the dichloromethane extract encourage us to consider these compounds as promising candidates for anti-TB drugs. Compound (3) showed a low activity against $M$. tuberculosis, which is in agreement with a previous study. In addition, Lin et al. (2001), working with natural biflavonoids isolated from the seed kernels of Rhus succedanea and Garcinia multiflora, which included compound (3), observed no activity against $M$. tuberculosis $\mathrm{H}_{37} \mathrm{Rv}$.

Although compounds (1) and (2) showed MICs higher than those of the reference drug isoniazid (MIC 0.01-0.2 $\mu \mathrm{g} / \mathrm{mL}$ ), these compounds are comparable to the MICs of other first-line anti-TB drugs, such as pyrazinamide
$($ MIC $20-100 \mu \mathrm{g} / \mathrm{mL}$ at $\mathrm{pH}=5.5$ or 6.0$)($ Inderlied \& Salfinger 1999).

As observed in this study, the MIC values for the resistant isolates, of which five were MDR, were equivalent to those of the sensitive isolates. This encourages us to consider these compounds as potential candidates for the development of new anti-TB drugs that act against
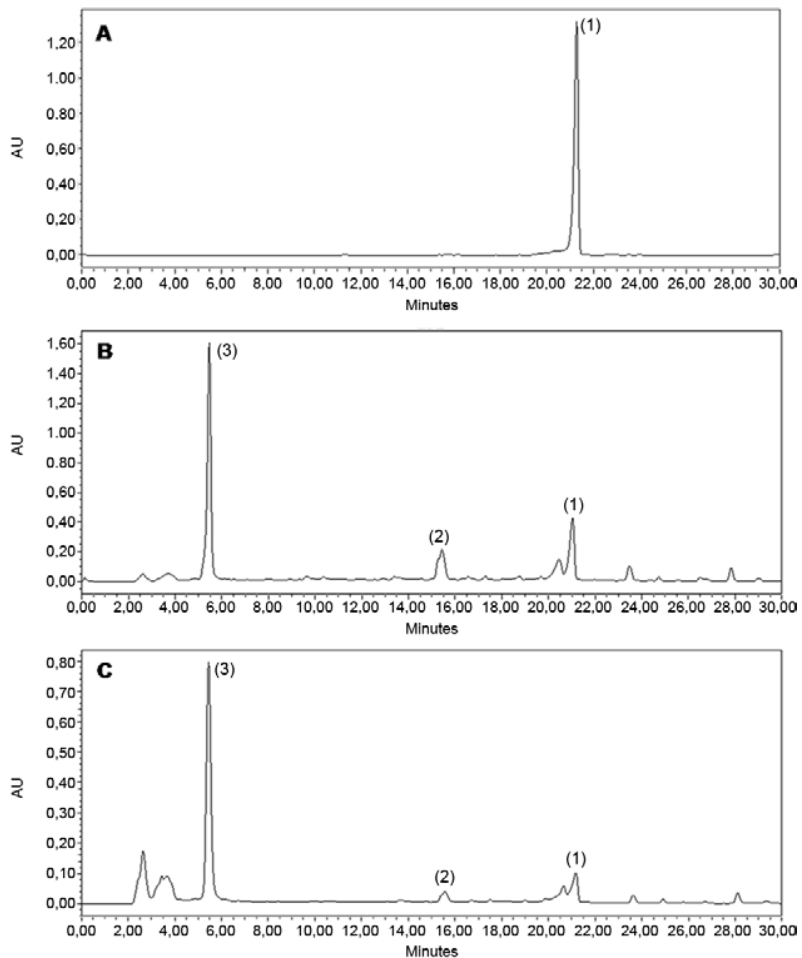

Fig. 2: chromatograms of the standard (-) mammea $A / B B\left(R_{t}=21.3\right.$ $\mathrm{min}$ (A) and dichloromethane (B) and aqueous (C) extracts from leaves of Calophyllum brasiliense. Chromatographic conditions: MetaSil ODS column; mobile phase: acetonitrile-water $55: 45 \mathrm{v} / \mathrm{v}$ to 80:20 (0-10 $\mathrm{min})$, $80: 20 \mathrm{v} / \mathrm{v}$ to $100 \%(10-20 \mathrm{~min}), 100 \%$ acetonitrile $(20-25 \mathrm{~min})$ and $55: 45$ $\mathrm{v} / \mathrm{v}(26-30 \mathrm{~min})$; flow rate $0.6 \mathrm{~mL} / \mathrm{min}$; temperature $25^{\circ} \mathrm{C}$; detection: 336 nm; (1): (-) mammea A/BB; (2): (-) mammea B/BB; (3) amentoflavone.

TABLE I

Anti-Mycobacterium tuberculosis H37Rv activity and cytotoxicity of extracts and pure compounds obtained from leaves of Calophyllum brasiliense

\begin{tabular}{lccc}
\hline $\begin{array}{l}\mathrm{MIC} \\
\text { Extracts/compounds }\end{array}$ & $\begin{array}{c}\mathrm{IC}_{50} \mu \mathrm{g} / \mathrm{mL} \pm \mathrm{SD} \\
(\mu \mathrm{M} \pm \mathrm{SD})\end{array}$ & $\mathrm{SI}$ \\
\hline $\begin{array}{l}\text { Extracts } \\
\quad \text { Dichloromethane }\end{array}$ & & $36.67 \pm 4.71$ & 0.59 \\
$\quad$ Aqueous & 62.5 & $\mathrm{NT}$ & $\mathrm{NT}$ \\
Pure compounds & 125.0 & & 1.06 \\
$\quad(-)$ mammea A/BB & $31.2(76.85)$ & $33.30 \pm 3.30(82.51 \pm 8.0)$ & 0.88 \\
$\quad-)$ mammea B/BB & $31.2(83.87)$ & $27.50 \pm 2.50(73.92 \pm 6.7)$ & $\mathrm{NT}$ \\
Amentoflavone & $>500$ & $\mathrm{NT}$ & \\
\end{tabular}

results are expressed as mean of experiments performed in triplicate. $\mathrm{IC}_{50}: 50 \%$ cytotoxic concentration; MIC: minimal inhibitory concentration; NT: not tested; SD: standard deviation; $\mathrm{SI}: \mathrm{IC}_{50} / \mathrm{MIC}$. 
TABLE II

Anti-Mycobacterium tuberculosis clinical isolates activity of isoniazid and pure compounds obtained from leaves of Calophyllum brasiliense

\begin{tabular}{|c|c|c|c|c|}
\hline \multirow{2}{*}{$\begin{array}{l}\text { M. tuberculosis } \\
\text { clinical isolates }\end{array}$} & \multirow{2}{*}{$\begin{array}{l}\text { Susceptibility } \\
\text { profile }\end{array}$} & \multicolumn{3}{|c|}{$\begin{array}{c}\text { MICs } \\
\mu \mathrm{g} / \mathrm{mL}(\mu \mathrm{M})\end{array}$} \\
\hline & & $\mathrm{H}$ & (1) & (2) \\
\hline 1 & Susceptible & $0.03(0.22)$ & $31.2(76.85)$ & $31.2(83.87)$ \\
\hline 13638 & Susceptible & $0.03(0.22)$ & 62.5 (153.94) & $62.5(168.01)$ \\
\hline 3 & Susceptible & $0.03(0.22)$ & $31.2(76.85)$ & $31.2(83.87)$ \\
\hline 11 & Susceptible & $0.03(0.22)$ & $31.2(76.85)$ & $31.2(83.87)$ \\
\hline 16 & Susceptible & $0.03(0.22)$ & $31.2(76.85)$ & $31.2(83.87)$ \\
\hline 4851 & Susceptible & $0.03(0.22)$ & $62.5(153.94)$ & 31.2 (83.87) \\
\hline 1193 & $\mathrm{H}, \mathrm{R}, \mathrm{E}, \mathrm{S}$ & $1(7.29)$ & $62.5(153.94)$ & $62.5(168.01)$ \\
\hline 91 & H, S & $2(14.58)$ & $62.5(153.94)$ & $31.2(83.87)$ \\
\hline 3614 & $\mathrm{H}, \mathrm{R}, \mathrm{E}, \mathrm{S}, \mathrm{Et}$ & $1(7.29)$ & $31.2(76.85)$ & $31.2(83.87)$ \\
\hline 4250 & $\mathrm{H}, \mathrm{R}$ & $2(14.58)$ & $31.2(76.85)$ & $31.2(83.87)$ \\
\hline $73 \mathrm{~A}$ & $\mathrm{H}, \mathrm{R}, \mathrm{Z}$ & $4(29.17)$ & $31.2(76.85)$ & $31.2(83.87)$ \\
\hline 17 & $\mathrm{H}$ & $2(14.58)$ & $62.5(153.94)$ & $31.2(83.87)$ \\
\hline 40 & $\mathrm{H}, \mathrm{R}$ & $2(14.58)$ & $62.5(153.94)$ & $31.2(83.87)$ \\
\hline
\end{tabular}

results are expressed as mean of experiments performed in triplicate. E: ethambutol; Et: ethionamide; H: isoniazid; MIC: minimal inhibitory concentration; R: rifampicin; S: streptomycin; Z: pyrazinamide; (1): (-) mammea A/BB; (2): (-) mammea B/BB.

resistant bacilli. A drug that can target these bacilli is undoubtedly desirable because this severe form of TB has been increasing worldwide.

The SI is used to estimate the therapeutic window of a drug and to identify drug candidates for further studies. According to Orme (2001), Protopopova et al. (2005) and García et al. (2012), a candidate as a new drug must have an $\mathrm{SI} \geq 10$. The extract and pure compounds studied here exhibited lower SIs, indicating low therapeutic selectivity. However, these compounds deserve attention and, in the future, a microparticles study of these compounds, as well as the antitumour activity will be conducted.

Here we report the activity of extracts and coumarins from the leaves of $C$. brasiliense against $M$. tuberculosis. The results of this study provide a strong basis for the selection of new anti-TB drugs. Additional studies are required to increase the effectiveness of coumarins against M. tuberculosis and to decrease their toxicity to a host.

\section{ACKNOWLEDGEMENTS}

To the Laboratory of Clinical Immunology of the State University of Maringá, Brazil.

\section{REFERENCES}

Boogaard JVD, Kibiki GS, Kisanga ER, Boeree MJ, Aarnoutse RE 2009. New drugs against tuberculosis: problems, progress and evaluation of agents in clinical development. Antimicrob Agents Chemother 53: 849-862.

Brenzan MA, Ferreira ICP, Lonardoni MVC, Honda PA, RodriguezFilho E, Nakamura CV, Dias-Filho BP, Ueda-Nakamura T, Cortez DAG 2008a. Activity of extracts and coumarins from the leaves of Calophyllum brasiliense camb on Leishmania braziliensis. Pharm Biol 46: 380-386.
Brenzan MA, Nakamura CV, Dias-Filho BP, Ueda-Nakamura T, Young MCM, Correa AG, Alvim-Júnior J, Santos AO, Cortez DAG 2008b. Structure-activity relationship of (-) mammea A/BB derivatives against Leishmania amazonensis. Biomed Pharmacother 62: 651-658.

Brenzan MA, Nakamura CV, Dias-Filho BP, Ueda-Nakamura T, Young MCM, Cortez DAG 2007. Antileishmanial activity of crude extract and coumarin from Calophyllum brasiliense leaves against Leishmania amazonensis. Parasitol Res 101: 715-722.

Brenzan MA, Nakamura CV, Dias-Filho BP, Ueda-Nakamura T, Young MCM, Mitsui ML, Cortez DAG 2010. Quantitative and qualitative analysis of (-) mammea $\mathrm{A} / \mathrm{BB}$ coumarin in extracts of Calophyllum brasiliense cambess (Clusiaceae) by HPLC. J Liq Chromatogr Relat Techno 33: 1-13.

Brenzan MA, Santos AO, Nakamura CV, Dias-Filho BP, Ueda-Nakamura T, Young MCM, Côrrea AG, Alvim-Júnior J, MorgadoDíaz JA, Cortez DAG 2012. Effects of (-) mammea A/BB isolated from Calophyllum brasiliense leaves and derivatives on mitochondrial membrane of Leishmania amazonensis. Phytomedicine 19: 223-230.

Corrêa MP 1978. Dicionário das plantas úteis do Brasil e das exóticas cultivadas, 1st ed., Imprensa Nacional, Rio de Janeiro, 388 pp.

Cottiglia F, Dhanapal B, Sticher O, Heilmann J 2004. New chromanone acids with antibacterial activity from Calophyllum brasiliense. J Nat Prod 67: 537-541.

Crombie L, Jones RCF, Palmer CJ 1987. Synthesis of the Mammea coumarins. Part 1. The coumains of the Mammea A, B and C series. J Chem Soc Perkin Trans 1: 317-331.

Cronquist A 1981. An integrated system of classification of flowering plants, Columbia University Press, New York, 1262 pp.

García A, Bocanegra-García V, Palma-Nicolás JP, Rivera G 2012. Recent advances in antitubercular natural products. Eur $J$ Med Chem 49: 1-23. 
Gasparotto-Júnior A, Brenzan MA, Ferreira ICP, Cortez DAG 2005. Estudo fitoquímico e avaliação da atividade moluscicida do Calophyllum brasiliense camb (Clusiaceae). Quim Nova 28: 575-578.

Honda PA, Ferreira IC, Cortez DAG, Amado CAB, Silveira TGV, Brenzan MA, Lonardoni MVC 2010. Efficacy of components from leaves of Calophyllum brasiliense against Leishmania (Leishmania) amazonensis. Phytomedicine 17: 333-338.

Inderlied CB, Salfinger M 1999. Antimycobacterial agentes and susceptibility tests. In PR Murray (ed.), Manual of clinical microbiology, 7th ed., ASM Press, Washington DC, p. 1601-1623.

León-Díaz R, Meckes M, Said-Fernández S, Molina-Salinas GM, Vargas-Villarreal J, Torres J, Luna-Herrera J, Jiménez-Arellanes A 2010. Antimycobacterial neolignans isolated from Aristolochia taliscana. Mem Inst Oswaldo Cruz 105: 45-51.

Lewis WH 1977. Medical botany-plants affecting man's health, John Wiley \& Sons, New York, 515 pp.

Lin YM, Falvin MT, Cassidy CS, Mar A, Chen FC 2001. Biflavonoids as novel antituberculosis agentes. Bioorg Med Chem Lett 11: 2101-2104.

Mosmann T 1983. Rapid colorimetric assay for cellular growth and survival: application to proliferation and cytotoxicity assays. J Immunol Methods 65: 55-63.

Noldin VF, Isaias DB, Cechinel-Filho V 2006. Gênero Calophyllum: importância química e farmacológica. Quim Nova 29: 549-554.

Orme I 2001. Search for new drugs for treatment of tuberculosis. Tuberculosis drug screening program. Antimicrob Agents Chemother 45: 1943-1946.

Palomino JC, Martin A, Camacho M, Guerra H, Swings J, Portaels F 2002. Resazurin microtiter assay plate: simple and inexpensive method for detection of drug resistance in Mycobacterium tuberculosis. Antimicrob Agents Chemother 46: 2720-2722.
Papazisis KT, Geromichalos GD, Dimitriadis KA, Kortsaris AH 1997. Optimization of the sulforhodamine B colorimetric assay. J Immunol Methods 208: 151-158.

Pretto JB, Cechinel-Filho V, Noldin VF, Sartori MRK, Isaias DEB, Cruz BA 2004. Antimicrobial activity of fractions and compounds from Calophyllum brasiliense (Clusiaceae/Guttiferae). $Z$ Naturforsch C 59: 657-662.

Protopopova M, Hanrahan C, Nikonenko B, Samala R, Chen P, Gearhart J, Einck L, Nancy CA 2005. Identification of a new antitubercular drug candidate, SQ109, from a combinatorial library of 1,2-ethylenediamines. J Antimicrob Chemother 56: 968-974.

Reyes-Chilpa R, Estrada-Muñiz E, Apan TR, Amekraz B, Aumelas A, Jankowski CK, Vásquez-Torres M 2004. Cytotoxic effects of mammea type coumarins from Calophyllum brasiliense. Life Sci 75: $1635-1647$

Scodro RBL, Pires CTA, Carrara VS, Lemos COT, Cardozo-Filho L, Souza VA, Corrêa AG, Siqueira VLD, Lonardoni MVC, Cardoso RF, Cortez DAG 2013. Anti-tuberculosis neolignans from Piper regnelli. Phytomedicine 20: 600-604.

Tiuman TS, Brenzan MA, Ueda-Nakamura T, Filho BP, Cortez DA, Nakamura CV 2012. Intramuscular and topical treatment of cutaneous leishmaniasis lesion in mice infected with Leishmania amazonensis using coumarin (-) mammea A/BB. Phytomedicine 19: 1196-1199.

WHO - World Health Organization 2012. Global tuberculosis report 2012, WHO, Geneva, 272 pp.

Xu ZQ, Barrow WW, Suling WJ, Westbrook L, Barrow E, Lin YM, Flavin MT 2004. Anti-HIV natural product $(+)$ calanolide A is active against both drug-susceptible and drug-resistant strains of Mycobacterium tuberculosis. Bioorg Med Chem 12: 1199-1207.

Yasunaka K, Abe F, Nagayama A, Okabe H, Lozada-Pérez L, López-Villafranco E, Muñiz EE, Aguilar A, Reyes-Chilpa R 2005. Antibacterial activity of crude extracts from Mexican medicinal plants and purified coumarins and xanthones. J Ethnopharmacol 97: 293-299. 